\title{
Interaction of exogenous factors (light and temperature) in their influence on the daily pattern of adult eclosion in Trichogramma embryophagum (Hymenoptera: Trichogrammatidae)
}

\author{
SVETlanA G. KARPOVA ${ }^{1}$ and SERgEY YA. REZNIK ${ }^{2}$ \\ ${ }^{1}$ Institute of Biology, Karelian Research Centre, Russian Academy of Sciences, 185610, Pushkinskaya, 11, Petrozavodsk, Russia; \\ e-mail: skarpova@krc.karelia.ru \\ ${ }^{2}$ Zoological Institute, Russian Academy of Sciences, 199034, St. Petersburg, Russia; e-mail: reznik@weed.zin.ras.spb.ru
}

Key words. Parasitoids, Hymenoptera, Trichogramma, eclosion, circadian rhythms, exogenous effects

\begin{abstract}
A comparative study of the direct influence of single, non-repetitive changes of light and/or temperature on the daily pattern of adult eclosion was conducted in laboratory conditions with the egg parasitoid, Trichogramma embryophagum (Hartig). In all experiments, the entire development occurred under the same regimen $\left(12 \mathrm{~L}: 12 \mathrm{D}, 20^{\circ} \mathrm{C}\right)$. However, just in the day when records of eclosion were made, the time of light-on was changed (from the total absence of a dark period to the 12-h-long scotophase). In addition, in different treatments of each experiment a thermophase $\left(30^{\circ} \mathrm{C}\right.$ during 2 or 4 hours) was applied in various positions relative to light-on. Results showed that light-on or a temperature step-up could induce eclosion in a certain percentage of individuals practically at any time of the 24-h-long cycle (masking effects). The fraction of adults emerging during $2 \mathrm{~h}$ after the beginning of the action of an exogenous factor depended not only on the preceding scotophase duration, but also on the stimulus itself (light, temperature or both). The temperature stimulus was found to modify the responsiveness to light considerably, depending on the order of application of the stimuli. The simultaneous action of light-on and a temperature step-up exerted a more considerable influence than could be expected based on their separate impacts. On the contrary, a high temperature pulse preceding the onset of the photophase inhibited the response of individuals to light-on, evidently acting by phase delay of a circadian rhythm of light responsiveness. These effects were more pronounced in the first half of the 12-h-long scotophase. The data suggest a complex interaction between the exogenous factors in their influence on the daily pattern of adult eclosion.
\end{abstract}

\section{INTRODUCTION}

Circadian rhythms are common in living organisms. They are known to be generated by the endogenous timing mechanisms (clocks or oscillators), which maintain free-running rhythms with a period of about $24 \mathrm{~h}$ under constant conditions. Many internal clocks form a complex circadian system in each organism and provide synchronisation of life processes and adaptation to environmental cycles (Plautz et al., 1997; Giebultowicz, 1999; Edery, 2000). The understanding of the construction and function of clock mechanism was greatly facilitated by comprehensive studies of insect rhythmicity, especially the rhythm of adult eclosion (Saunders, 1982).

It is known that the circadian timing system is composed of three interconnected parts: 1) input pathways that can receive and transmit environmental cues, such as light and temperature; 2) the clock (pacemaker) itself and 3) effector pathways that manifest overt rhythms. In the case of adult eclosion, the clock controls rhythmicity through neuroendocrine pathways (Truman et al., 1981; Jackson et al., 2001). The phase of endogenous oscillations can be changed by the influence of light and temperature, which act therefore as entraining agents, or zeitgebers. On the other hand, environmental factors can cause direct behavioural or physiological responses, termed as "masking effects" (Aschoff, 1960). Thus, overt rhythms involve a mixture of endogenous and exogenous components (Beck, 1980; Saunders, 1982).
As in many insects, species of the hymenopteran egg parasitoid Trichogramma were proved to possess distinct eclosion rhythmicity of truly endogenous nature. This circadian rhythm can be synchronised with the external photo- or thermoperiod so that the maximum of emergence usually occurs near the onset of the photo- or thermophase (Rounbehler \& Ellington, 1973; Forsse \& Smith, 1991; Tavares \& Voegele, 1991; Dahiya et al., 1993; Corrigan et al., 1995; Pompanon et al., 1995, Reznik et al., 1998). However, light-on or a temperature step-up can induce eclosion in a considerable fraction of individuals practically at any time of day, thus significantly modifying the pattern of the overt rhythm (Zaslavski et al., 1999).

The mechanism of such exogenous stimulation still remains unclear in Trichogramma, as well as in other insects. There are several lines of evidence that light and temperature can cause changes in activity bypassing the circadian system (Morris \& Takeda, 1994; McNabb \& Truman, 2000). Nevertheless, the magnitude of these responses does depend on the phase of the circadian oscillation (Germ \& Tomioka, 1998a, 1998b). The masking effect of light is also dependent on the average temperature (Riihimaa, 1996; Lankinen \& Riihimaa, 1997; Tomioka et al., 1998).

The findings on the mechanisms of the exogenous effects were obtained in experiments with one factor (e.g. light) varied while another (e.g. temperature) remained 


$$
\text { a }
$$


constant. In nature, however, an overt rhythm in insects can be greatly modified by the responses to repetitive and irregular changes of both factors. To elucidate the processes underlying the plasticity of a rhythm, it is therefore necessary to conduct the experiments with combined influence of light and temperature stimuli.

Such experimental work has been conducted previously, but only with joint light and temperature cycles repeated daily (Pittendrigh, 1960; Moore \& Rankin, 1993; Zaslavski et al., 1995; Roces \& Nunez, 1996; Zinovjeva et al., 1996). The results obtained in these experiments facilitate an understanding of the mechanisms controlling the entrainment of circadian oscillators, but provide no information about the capacity of a rhythm to be modified immediately by unpredictable influence of the stimuli. Thus, the question of how the non-repetitive changes of both light and temperature interact in their influence on the pattern of a rhythm still remains unsolved.

The present work was designed to investigate one of the aspects of this problem: how a temperature stimulus (high temperature pulse) of different position and duration modifies the masking effect induced by a light stimulus (light-on), in the rhythm of adult eclosion in Trichogramma embryophagum.

\section{MATERIAL AND METHODS}

The laboratory strain of the parthenogenetic species $T$. embryophagum (Hartig), used in this study, originated from Moscow province. The parasitoid was reared on eggs of Sitotroga cerealella Oliv. (Gelechiidae). For parasitization the host eggs glued on paper cards were placed for 24 hours into a cage with newly emerged females of Trichogramma. Then the cards were put into glass tubes and transferred to experimental conditions (thermostatic chambers) under the same regime $(12 \mathrm{~L}$ $\left.12 \mathrm{D}, 20^{\circ} \mathrm{C}\right)$. Illumination was provided by fluorescent lights $(50$ $1 \mathrm{x})$.

Just in the day when records of emergence were made, the period of darkness (scotophase) was changed from 0 to $12 \mathrm{~h}$ in different experiments and then light was turned on continuously until the end of the observations.

Five series of experiments were designed (see the horizontal bars on the x-axes of Fig. 1 and 2):

A) constant temperature of $20^{\circ} \mathrm{C}$ throughout the experiment (control);

B) 2-h-long high temperature pulse $\left(30^{\circ} \mathrm{C}\right)$ just before the light-on;

C) 2-h-long high temperature pulse $\left(30^{\circ} \mathrm{C}\right)$ just after the light-on;
D, E) high temperature pulse $\left(30^{\circ} \mathrm{C}\right)$ at the onset of the scotophase (temperature pulses of 2 or $4 \mathrm{~h}$ were used in Series D and $\mathrm{E}$, correspondingly).

In Series $\mathrm{A}$ and $\mathrm{E}$, more prolonged experiments were also conducted, with light-on applied at different times from 2 to 24 hours after light-off in different treatments.

The temperature was changed by transferring the tubes between the chambers with different temperature but the same light intensity. In the treatments with a temperature pulse applied before light-on the tubes were transported inside lightproof parcels, in which they were put just after light-off.

In all experiments, individuals emerging by the onset of the scotophase were removed from the tubes simultaneously. After light-on in a given experiment the number of adults eclosing during the scotophase was counted. However, in the treatments with a temperature pulse applied just before light-on, the first records were made in darkness, $2 \mathrm{~h}$ before the onset of the photophase. In this case the number of emerged individuals was counted under dim red light, when the tubes were transferred to the $30^{\circ} \mathrm{C}$ chamber in the light-proof parcels and left there until the light-on.

After light-on in a given experiment, records were made every two hours and finished in all experiments at the same time, $24 \mathrm{~h}$ after the last light-off. The more prolonged experiments $(48 \mathrm{~h}$ ) were organised only for Series A and E (see above).

By these experiments it was possible to estimate the response of individuals to a light-on or a temperature step-up at different times during the 24-h-long cycle. Moreover, this arrangement allows us to reveal how the high temperature pulse of different position and duration can modify the effect of light-on.

To estimate the influence of a high temperature pulse on the responsiveness to the light stimulus, it is first necessary to define the parameter of such sensitivity. In most studies concerning behavioural responses of insects to various stimuli, the percentage of responding individuals observed during a short period of time after a stimulation was used (Brady, 1972, 1975, 1978; Fitt, 1981; Zhukovskaya, 1995). However, our results on the masking effect of light on the adult eclosion in Trichogramma have shown that it is possible to define the response to light-on by two parameters. The first one is an immediate response to the stimulus (a fraction of specimens eclosing within $2 \mathrm{~h}$ after the beginning of the action of the exogenous factor) and the second is a latency from light-on to the median time of eclosion. In order to compare the responsiveness to light-on (and hence its masking effect) among the treatments, we shall use one of these parameters or both, depending on what appears to be more illustrative.

All experiments were replicated $2-5$ times and the results were summarised. On average 510 (minimum - 100) adults were recorded in each replicate of each treatment. In the figures, the rhythm is presented as a percentage of eclosed adults per 2 hours, relative to the total number of individuals emerging

Fig. 1. Modification of the daily dynamics of eclosion by light-on and/or a high temperature pulse applied at a various time after the light-off (Series A, B, C).

Photoperiodic regime in the day when records of eclosion were made is shown near the horizontal axis. Black, white and grey bars indicate scoto-, photo- and thermophases, correspondingly.

$\mathrm{A}$ - constant temperature of $20^{\circ} \mathrm{C} ; \mathrm{B}-2$-h-long high temperature pulse $\left(30^{\circ} \mathrm{C}\right)$ just before light-on; $\mathrm{C}-2$-h-long high temperature pulse $\left(30^{\circ} \mathrm{C}\right)$ just after light-on. Numbers on the right side of the plots indicate the duration of the scotophase in a given treatment.

The circles with the error bars are the median hour of eclosion with quartiles. The letters above the circles represent the comparison of medians relative to the light-off. Medians are not significantly different ( $p>0.05$, Kruskal-Wallis test) if they are followed by the same letter. Roman and Greek letters are for the comparison between treatments of the same column (within a series) and of the same row (among different series), correspondingly.

The lines conmecting the circles show the shift of an eclosion median time with change of light-on position. 
A
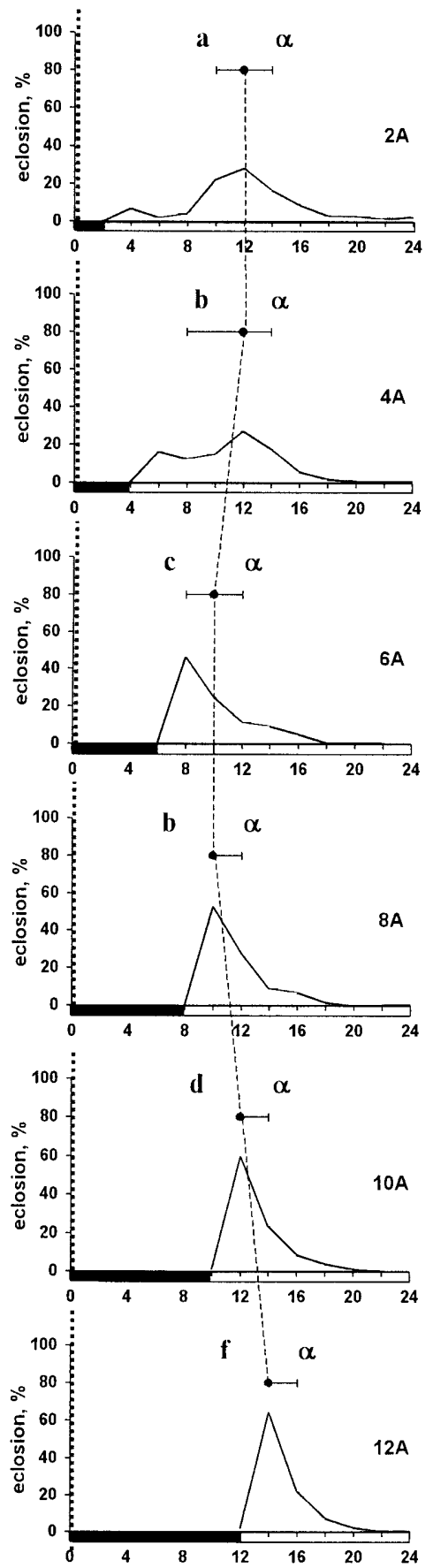

Time, hours from light-off

A

D
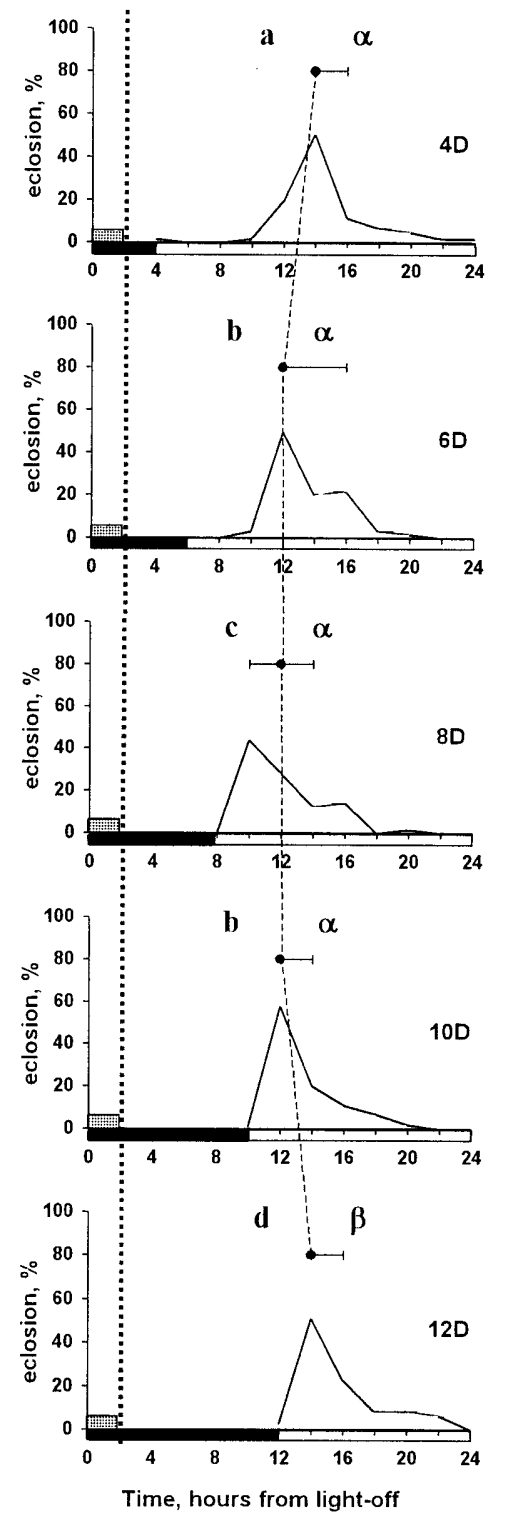

Fig. 2. Modification of the daily dynamics of eclosion by light-on and/or a high temperature pulse applied at a various time after the light-off (Series A, D, E).

A - constant temperature of $20^{\circ} \mathrm{C}$ (control); D - 2-h-long high temperature pulse $\left(30^{\circ} \mathrm{C}\right.$ ) at the onset of scotophase; $\mathrm{E}-4$-h-long high temperature pulse $\left(30^{\circ} \mathrm{C}\right)$ at the onset of scotophase. Numbers on the right side of the plots indicate the duration of the scotophase in a given treatment.

The circles with the error bars are the median hours of eclosion with quartiles, relative to the light-off. The letters above a circle represent the comparison of medians relative to the time, indicated by a vertical dotted line (light-off in Series A, temperature stepdown in Series D,E). Medians are not significantly different ( $\mathrm{p}>0.05$, Kruskal-Wallis test) if they are followed by the same letter. Roman and Greek letters are for the comparison between treatments of the same column (within a series) and of the same row (among different series), correspondingly.

The lines connecting the circles show the shift of an eclosion median time with change of light-on position.

For further explanations see the text. 


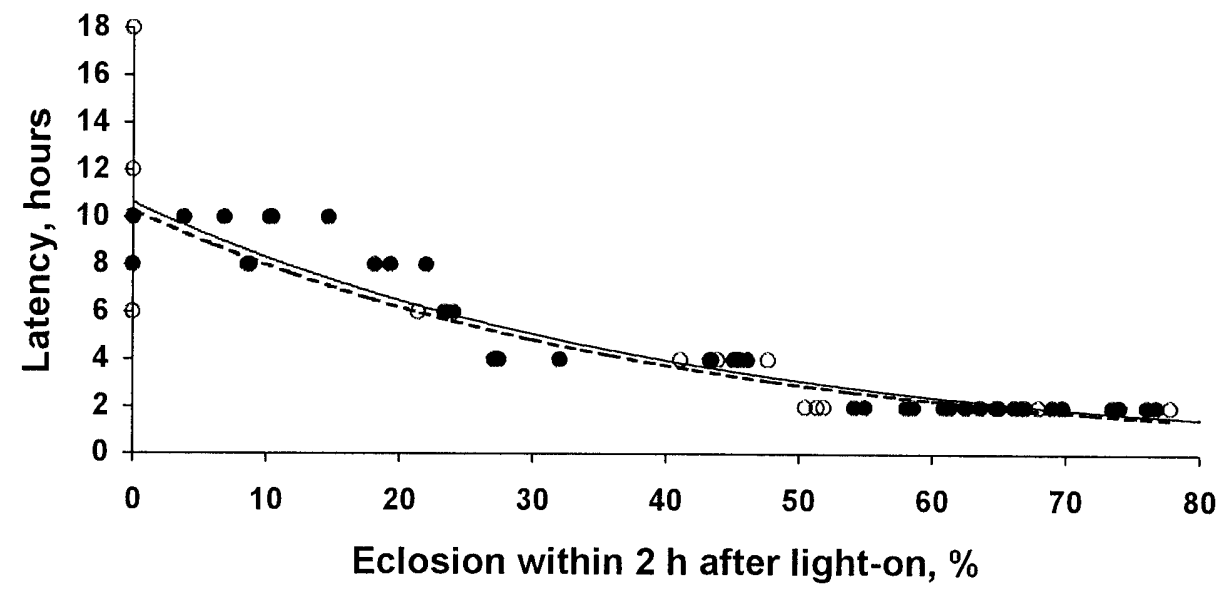

Fig. 3. Relationship between the magnitude of immediate response to the light stimulus and the latency from light-on to a median eclosion time.

Solid circles indicate the control treatments (Series A, constant temperature of $20^{\circ} \mathrm{C}$ ), open circles indicate the treatments with a high temperature pulse at the onset of scotophase (pooled data of Series D, E). Fraction of adults was calculated relative to the total number of adults eclosing during the period of records $(24 \mathrm{~h})$. The lines indicate the exponential trend for control (solid line, $\mathrm{y}=$ $10,62 \mathrm{e}^{-0,025 x} ; \mathrm{R}^{2}=0,92$ ) and experiment (broken line, $\mathrm{y}=10,26 \mathrm{e}^{-0,025 \mathrm{x}} ; \mathrm{R}^{2}=0,84$ ).

during the period of the observation. The median was used instead of mean in the estimation of the phase of eclosion peak, because the distributions were often skewed. Median time of eclosion was compared among treatments by Kruskal-Wallis test. The comparison between fraction of adults eclosing within a given time period in different experiments was made by ANOVA test after arcsines transformation.

\section{RESULTS}

\section{Series "A" experiments: eclosion under a constant temperature of $20^{\circ} \mathrm{C}$ (control)}

Results of experiments conducted under a constant temperature of $20^{\circ} \mathrm{C}$ are shown on the left column of Fig. 1. In the treatment with complete absence of a dark period, the number of eclosed adults proceeded gradually throughout the observation period, without any distinct peaks. After a short period of darkness $(2 \mathrm{~h})$ light-on induced a rather weak response, median eclosion time following light-on with latency of 10 hours. With a further increase of the scotophase duration the immediate response to light-on gradually intensified and the median shifted to the beginning of the photophase. After the 12$\mathrm{h}-$ long scotophase the light stimulus evoked eclosion in $65 \%$ of adults.

The relationship between the immediate response to the stimulus and the latency to the median was best fitted by exponential trend (Fig. 3). With increase of the magnitude of the response, the latency exponentially reduced. A similar correlation was obtained in treatments with the constant temperature (Series A) and a high temperature pulse (Series D and E). Hereafter, when comparing the results of these Series, we shall use the phase of eclosion relative to the onset of the photophase as an indirect parameter of sensitivity to the light stimulus (see the "Discussion").

\section{Series "B" experiments: 2-h-long high temperature pulse just before the light-on}

Results of treatments where light-on was preceded by a 2-h-long high temperature pulse are shown in Fig. 1, column "B". In all treatments, except the one with total absence of a scotophase, the temperature perturbations caused significant modification of the eclosion pattern, in comparison with the controls $(\mathrm{p}<0.05$, Kruskal-Wallis test). Like the light stimulus, a rise of temperature in darkness induced eclosion in a certain fraction of adults, the response increasing with the time elapsed since light-off (see the points, corresponding with the end of the thermophase on the curves in Fig. 1, column "B"). Interestingly, in experiments with short (less than $8 \mathrm{~h}$ ) scotophases a temperature pulse caused minor masking effect, but seemed to inhibit the response to the subsequent light-on. This effect was expressed both in the reduced immediate response to the light stimulus ( $\mathrm{p}<$ 0.05 , ANOVA) and the prolonged latency to a median eclosion time ( $p<0.05$; Kruskal-Wallis test), in comparison with the controls. In treatments with more prolonged scotophases a temperature pulse evoked eclosion in a considerable fraction of adults in darkness, therefore emergence started earlier than in the controls $(\mathrm{p}<0.05$; Kruskal-Wallis test), with reducing the response to the following stimulus (light-on) ( $\mathrm{p}<0.05$, ANOVA).

\section{Series " $C$ " experiments: 2-h-long high temperature pulse just after the light-on}

Column " $C$ " in Fig. 1 shows the results of experiments where light-on coincided with the beginning of the high temperature pulse. It is apparent from these data that the temperature step-up considerably enhanced the effect of the light stimulus. A strongly pronounced response to the joint influence of the stimuli was recorded even in the treatments with short ( 2 and $4 \mathrm{~h}$ ) scotophases. 


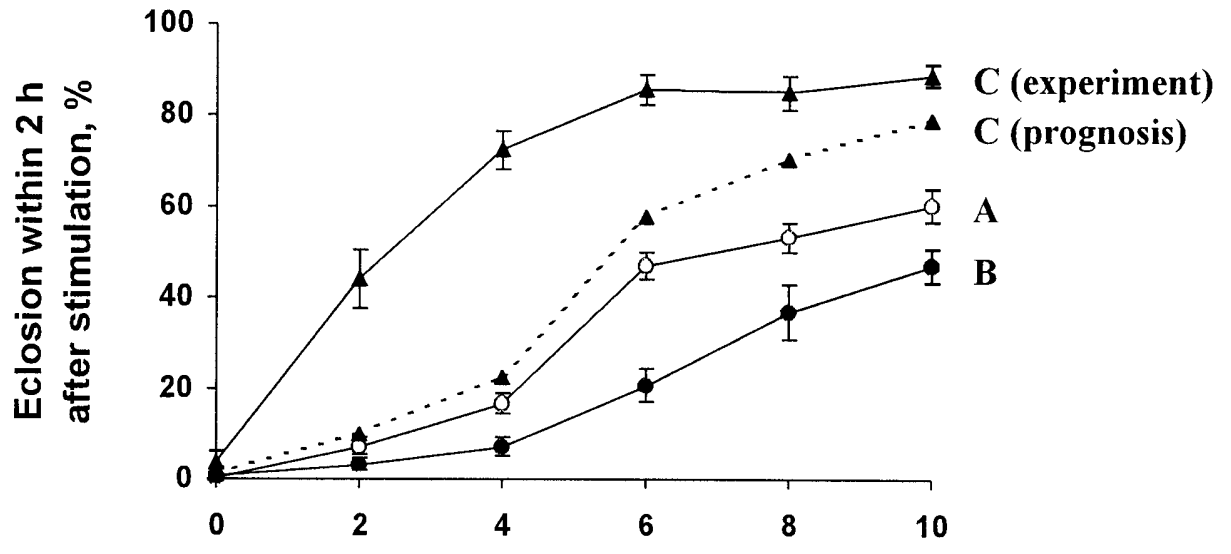

Time of stimulation, hours after light-off

Fig. 4. Daily changes in the responsiveness to single or joint action of the light and temperature stimuli.

A - light-on stimulus; B - temperature step-up in darkness; C - simultaneous light-on and temperature step-up (the data were obtained in the series marked by correspondent letters).

"C prognosis" - a theoretical prediction of response to join action of the stimuli, based on the assumed independent impacts of the factors, "C experiment" - experimental data.

On the ordinate, there is a percentage of adults, eclosing within 2 hours after the stimulus application at a given hour, relative to the total number of adults eclosing during $24 \mathrm{~h}$ after light-off. The error bars indicate confidence intervals.

For further explanations see the text.

To examine if this activating effect of temperature is merely a summation of the stimuli impacts, we compared an immediate response to a single factor (light-on or temperature step-up in darkness) and to the stimuli applied simultaneously. The fraction of specimens eclosing within $2 \mathrm{~h}$ after the beginning of the action of exogenous factor(s) is shown in Fig. 4. The degree of response increased with the prolongation of the scotophase. In general, light-on exerted a more considerable influence than a temperature rise. The broken line denotes the theoretical predictions of fraction of individuals, eclosing within 2 hours after a stimulation of both factors, estimated from the standard formula of percentages addition:

$$
\mathrm{P}(\mathrm{t}+\mathrm{ph})=\mathrm{P}(\mathrm{t})+\mathrm{P}(\mathrm{ph})((100-\mathrm{P}(\mathrm{t})) / 100, \text { where }
$$

$\mathrm{P}(\mathrm{t})$ - percentage of adults eclosing after the temperature rise in darkness (experimental data);

$\mathrm{P}(\mathrm{ph})$ - percentage of adults eclosing after the light-on (experimental data);

$\mathrm{P}(\mathrm{t}+\mathrm{ph})$ - percentage of eclosed adults, which is expected based on the assumed independent impacts of these factors (prognosis).

The data given in Fig. 4 strongly testify that the simultaneous action of light and temperature stimulus exerted a more significant influence, than could be expected if the factors acted independently.

\section{Series "D" and "E" experiments: high temperature pulse ( 2 or $4 \mathrm{~h}$ ) at the onset of scotophase}

These sets of experiments were designed to specify the inhibitory effect of high temperature on the responsiveness to the light stimulus, observed in the first half of the 12-h-long scotophase (Series "B" experiments).

The results are shown in Fig. 2, columns " $D$ " and "E". A high temperature pulse at the onset of the scotophase did not cause eclosion in darkness, but inhibited the response to the light stimulus applied several hours later (compare the diagrams with an equal scotophase duration, placed diagonally in Fig. 2). The effect was expressed as a reduced immediate response to light-on (in all treatments except "10D", there was a significant difference in comparison with the controls, $\mathrm{p}<0.05$, ANOVA) and prolonged latency to a median eclosion time (in treatments with scotophase less than $10 \mathrm{~h}, \mathrm{p}<0.05$, KruskalWallis test). For instance, after $6 \mathrm{~h}$ of darkness, light-on induced eclosion in $50 \%$ of adults in the control group, median eclosion time fell on $10 \mathrm{~h}$. At the same time, no response was observed in treatments with a temperature pulse, and the medians were at 12 and $16 \mathrm{~h}$ in variants "D" and "E", correspondingly (compare var. 6A, 6D and $6 \mathrm{E}$ in Fig. 2).

The median eclosion time appears to be in a phase relation with the temperature step-down. To illustrate this, the plots in Fig. 2 were so arranged that in the same row there are the treatments with different prolongation of scotophase, but with the same period from temperature stepdown to light-on (or, in the controls, from light-off to light-on). The eclosion distribution was compared among the treatments relative to a time denoted by a vertical dotted line. In most cases, there were no significant differences between treatments of the same row $(p>0.05$, Kruskal-Wallis test). This suggests that the latency from a light-on to a median in Series D and E was defined by not the whole duration of the scotophase, as in the controls, but by the "unaffected" part of the scotophase after the temperature drop.

Another parameter of the responsiveness, an immediate response to the light stimulus, was also found to be in a phase relation with temperature step-down. Fig. 5 shows the results of prolonged experiments of Series A and E. In 


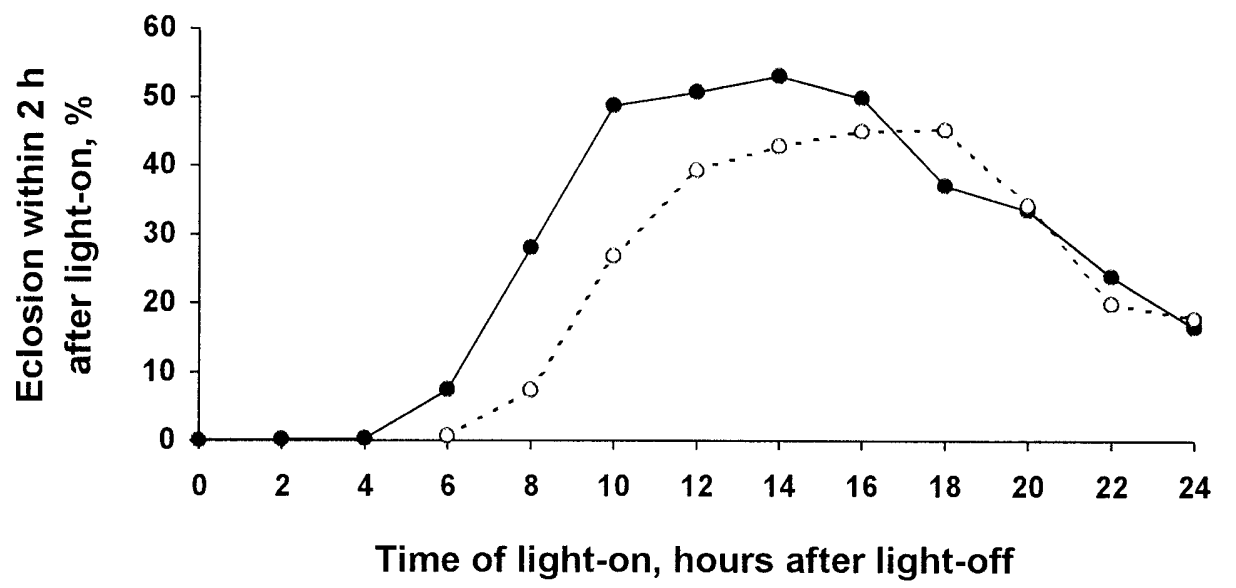

Fig. 5. Daily changes in responsiveness to the light-on stimulus.

Solid line is for control treatments (constant temperature of $20^{\circ} \mathrm{C}$, Series A), broken line is for experiments with 4-h-long high temperature pulse at the onset of the scotophase (Series E). On the ordinate, there is a percentage of adults, eclosing within 2 hours after light-on at a given hour, relative to the total number of adults eclosing during $48 \mathrm{~h}$ after light-off. The curves are based on 5 (control) or 3 (experiment) replicates and smoothed with 2-point sliding means.

both variants the degree of immediate response to light-on significantly changed throughout $24 \mathrm{~h}$ after the onset of darkness. In the treatment with a 4-h-long high temperature pulse the observed daily dynamics was evidently shifted to the later hours. A mean time of maximal responsiveness fell on $12.0 \pm 0.8$ (SEM) h under the constant temperature, but on $15.3 \pm 0.7 \mathrm{~h}$ if the thermophase was applied at the onset of darkness $(\mathrm{p}<0.05$, $\mathrm{t}$-test $)$.

Thus, in experiments with a high temperature pulse applied at the onset of the scotophase the changes in the responsiveness were in the same phase relation with temperature drop, as with light-off in the controls.

\section{DISCUSSION}

\section{Daily changes in masking effect of light and temperature}

Results of this investigation have shown that the magnitude of the immediate response induced by light-on or/and a temperature rise in T. embryophagum depended on the time of stimulation. Just after light-off individuals exhibited weak sensitivity to light-on, intensity of the response increasing gradually peaking at $12 \mathrm{~h}$ after the light-off and then reduced again (Fig. 5). Similar changes were observed in response to a temperature step-up in darkness throughout the 12-h-long scotophase (Fig. 4).

The data are consistent with the previous findings that the response to various exogenous stimuli is under control of a circadian oscillation. For instance, circadian rhythmicity in insects has been documented for sex pheromone perception, probing and optokinetic responsiveness, sensitivity to drug and olfactory stimuli, etc. (Brady, 1975, 1978; Saunders, 1982; Zhukovskaya, 1995; Krishnan et al., 1999; Andretic \& Hirsh, 2000). Daily changes of the masking effect of the light stimulus were also demonstrated for behavioural and adult eclosion rhythms (Zotov, 1983; Morris \& Takeda, 1994; Germ \& Tomioka, 1998a). These modulations in responsiveness to light are thought to be caused by the circadian rhythms in sensi- tivity of visual system to light, which are well known in insects (Germ \& Tomioka, 1998a, 1998b; Pyza \& Cymborowski, 2001).

Such circadian changes in responsiveness to exogenous stimuli seem to be of adaptive significance preventing the response to occasional changes of environment at an inappropriate time (Tshernyshev, 1984).

\section{Modification of responsiveness to light-on by a high temperature pulse}

The experimental data indicate that two factors interacted in a complex manner, i.e. a high temperature pulse essentially affected the response of the individuals to light-on. Two opposite effects, especially pronounced in the first half of the 12-h-long scotophase, were observed, according to the position of the thermophase relative to the photophase.

\section{Activating effect of a high temperature pulse}

The response to the light stimulus was considerably enhanced when a temperature step-up and light-on were coincident. This effect exceeded the mere summation of single stimuli impacts (Fig. 4), suggesting that the influences of the two factors are converged by a certain integration mechanism. This is consistent with the previous findings that light and temperature information are apparently integrated on some levels of the circadian system (Ikeda \& Tomioka, 1993, Moore \& Rankin, 1993; Sidote et al., 1998; Tomioka et al., 1998).

Interestingly, the cumulative effect of the simultaneous actions of light and temperature changes was observed previously in the studies with daily synchronous changes of light and temperature (Moore \& Rankin, 1993; Zaslavski et al., 1995). For instance, when the adult eclosion rhythm in Trichogramma evanescens was synchronizing to several light cycles combining with a short thermophase at the onset of the photophase, an effect elicited by such entrainment significantly exceeded a simple sum of effects of single light or temperature cycle 
(Zaslavski et al., 1995). In the cited studies, however, it is difficult to establish the reason for an enhanced response, if it was caused by a masking effect of the two stimuli or by a synchronisation of a rhythm to both light and temperature cycles.

The mechanism of the cumulative effect observed in our and previous studies still remains unclear and requires further experimental work.

\section{Inhibitory effect of a high temperature pulse}

One of the most striking results obtained at the initial stage of this study was the fact that a 2-h-long high temperature pulse applied just before light-on significantly inhibited the response to the latter stimulus. This effect was differently expressed throughout the 12-h-long scotophase. Thus, in treatments with the period of darkness exceeding 8 hours, the decrease in a light-on response was apparently due to an advanced eclosion caused by the preceding temperature step-up in darkness. However, in the first half of the 12-h-long scotophase, the temperature stimulus induced eclosion only in a minor fraction of adults, but evidently inhibited the direct response to subsequent light-on and delayed a median eclosion time (Fig. 1, columns A and B).

To our knowledge, such an inhibitory influence of temperature is previously unknown, at least for the rhythm of eclosion. A plausible suggestion is that the temperature pulse affects a circadian pacemaker controlling a rhythm of responsiveness to the light stimulus. This is supported by the well known fact that single, non-repetitive temperature pulses or steps may cause phase shifts of circadian oscillators (Zimmerman et al., 1968; Wiedenmann \& Loher, 1984; Ikeda \& Tomioka, 1993; Sidote et al., 1998; Saunders \& Hong, 2000), although it has not been yet examined for the rhythm of light responsiveness.

To test this hypothesis, we designed two sets of experiments, in which a high temperature pulse of 2 or 4 hours was applied at the onset of the scotophase. The changes of responsiveness to the light stimulus after a pulse were investigated by the application of light-on at a various time after the end of the thermophase.

It turns out that in both experimental series the high temperature pulse did not cause direct response of individuals, but inhibited response to the subsequent light stimulus. Moreover, the dynamics of eclosion after light-on was found to bear exactly the same phase angle to the temperature step-down as to the light-off in the control (constant temperature of $20^{\circ} \mathrm{C}$ ). For instance, in the treatment with $4 \mathrm{~h}$ of $30^{\circ} \mathrm{C}$ at the onset of the 6-h-long scotophase and in the one with $2 \mathrm{~h}$ of $30^{\circ} \mathrm{C}$ at the onset of the 4-h-long scotophase eclosion proceeded after light-on in a similar way as if there was only $2 \mathrm{~h}$ of the dark period (compare var. 2A, 4D and 6E in Fig. 2).

As we used the position of median eclosion time relative to light-on as an indirect parameter of responsiveness to the light stimulus, it can be therefore concluded that the rhythm of responsiveness to light-on was in a phase relation with the temperature drop. Further evidence is that the daily changes in the fraction of individuals, responding immediately to light-on, was also significantly shifted by the temperature pulse to the later hours (Fig. 5).

The results obtained in these experiments strongly support the suggestion that a temperature pulse at the onset of the scotophase can modify the response to light by shifting the circadian rhythm of sensitivity to the latter stimulus. This point should be noted in further studies concerning combined influence of the two factors.

Generally, the present data suggest that the influence of temperature on the masking effect of light can be immediate or prolonged, activating or inhibiting, and apparently mediated at several levels of control. It is reasonable to expect a similar effect of light on the responsiveness to a temperature stimulus, although this suggestion requires further experimental verification.

\section{Adaptive value of the eclosion rhythm}

Eclosion in Trichogramma species occurs during the morning hours, as in many other diurnal insects (Saunders, 1982; Lankinen, 1986; Ruberson et al., 1988; Pompanon et al., 1995). This timing may have two advantages. First, in the morning, when the humidity is higher than in the middle of the day, the conditions are apparently more favourable for emergence, as they prevent the insects from too much loss of water (Lankinen, 1986). Secondly, eclosion at the onset of photophase allows the parasitoids to start their reproductive activity immediately, and thus reduces the risk of dying before laying eggs (Pompanon et al., 1995).

However, compared with other species studied so far, $T$. embryophagum possesses one conspicuous feature of the eclosion rhythm. In most insects, adult emergence was found to be under a rigid endogenous control, therefore it is restricted usually to a very narrow period of day, termed as "gates" (Pittendrigh, 1967; Saunders, 1982). On the contrary, the findings obtained in the present study suggest a great lability of mechanisms, controlling the rhythm of eclosion in T. embryophagum. Therefore, it is difficult to predict a precise time of emergence in this species. In many other aerial insects inhabiting northern regions, eclosion rhythms cannot be considered as a "gated" phenomenon, because of its high flexibility (Muller, 1973; Lankinen, 1986; Fischer et al., 1990). This feature may be of adaptive value, since in a northern climate it is important to react directly to favourable but unpredictable changes of environmental factors at any time of day (Riihimaa, 1996; Lankinen \& Riihimaa, 1997).

ACKNOWLEDGEMENTS. We are grateful to G.M. Shkarlat, O.I. Spirina and T.Ya. Umarova for technical support of these experiments. This study was supported in part by grants from the Russian Foundation of Basic Research (01-04-48050) and the Russian Federal Program "State Support for the Integration of Higher Education with Fundamental Science".

\section{REFERENCES}

ANDRETIC R. \& HrRSH J. 2000: Circadian modulation of dopamine receptor responsiveness in Drosophila melanogaster. Proc. Nat. Acad. Sci. USA 97:1873-1878. 
AsChOFF J. 1960: Exogenous and endogenous components in circadian rhythms. Cold Spring Harbor Symp. Quant. Biol. 25: 11-27.

Beck S.D. 1980: Insect Photoperiodism. Academic Press, New York, London, $387 \mathrm{pp}$

BRADY J. 1972: The visual responsiveness of the tsetse fly Glossina morsitans Westw. (Glossinidae) to moving objects: the effects of hunger, sex, host odour and stimulus characteristics. Bull. Entomol. Res. 62: 257-279.

Brady J. 1975: Circadian changes in central excitability the origin of behavioural rhythms in tsetse flies and other animals? J. Entomol. (A). 50: 79-95.

BraDY J. 1978: The control of the circadian activity rhythms in tsetse flies: environment or physiological clock? Physiol. Entomol. 3: 177-190.

Corrigan J.E., Laing J.E. \& Zubricky J.S. 1995: Effects of parasitoid to host ratio and time of day of parasitism on development and emergence of Trichogramma minutum (Hymenoptera: Trichogrammatidae) parasitizing eggs of Ephestia kuehniella (Lepidoptera: Pyralidae). Ann. Entomol. Soc. Am. 88: 773-780.

Damity A.S., Tshernyshev W.B. \& Afonina V.M. 1993: Diurnal rhythm of emergence from pupae in parasitic wasp. $J$. Interdiscipl. Cycle Res. 24: 162-170.

EDERY I. 2000: Circadian rhythms in a nutshell. Physiol. Genom. 3: 59-74.

Fischer J., INeicheN H. \& AdAmer G. 1990: Circadian clock and eclosion activity of Chironomus (Diptera: Chironomidae). Zool. Jb. Syst. 117: 317-329.

FitT G.P. 1981: The influence of age, nutrition and time of day on the responsiveness of male Dacus opiliae to the synthetic lure, methyl eugenol. Entomol. Exp. Appl. 30: 83-90.

Forsse E. \& SмITH S.M. 1991: Flight behaviour in Trichogramma minutum. Colloques de l'INRA 56: 65-66.

Germ M. \& Tomioka K. 1998a: Circadian period modulation and masking effects induced by repetitive light pulses in locomotor rhythms of the cricket, Gryllus bimaculatus. Zool. Sci. 15: $309-316$

Gerv M. \& TomoKa K. 1998b: Effects of 5,7-DHT injection into the optic lobe on the circadian locomotor rhythm in the cricket, Gryllus bimaculatus. Zool. Sci. 15: 317-322.

GieBuLtowiCz J.M. 1999: Insect circadian clocks: is it all in their head? J. Insect Physiol. 45: 791-800.

IKEDA M. \& TOMOKA K. 1993: Temperature dependency of the circadian locomotor rhythm in the cricket Gryllus bimaculatus. Zool. Sci. 10: 597-604.

Jackson F.R., Schroeder A.J., Roberts M.A., McNeil G.P., KUME K. \& ACTEN B. 2001: Cellular and molecular mechanisms of circadian control in insects. J. Insect Physiol. 47: 833-842.

KrishnaN B., Dryer S.E. \& Hardin P.E. 1999: Circadian rhythms in olfactory responses of Drosophila melanogaster. Nature 400: 375-378.

LANKINEN P. 1986: Geographical variation in circadian eclosion rhythm and photoperiodic adult diapause in Drosophila littoralis. J. Comp. Physiol.(A) 159: 123-142.

LANKINEN P. \& RImIMAA A. 1997: Effects of temperature on weak circadian eclosion rhythmicity in Chymomyza costata (Diptera: Drosophilidae). J. Insect Physiol. 43: 251-260.

MCNabB S.L. \& Truman J.W. 2000: Effects of light on eclosion and eclosion hormone neurones in Drosophila. Proc. Soc. Neurosci. 26: 373.

MoORE D. \& Rankin M.A. 1993: Light and temperature entrainment of a locomotor rhythm in honeybees. Physiol. Entomol. 18: $271-278$
MorRIS M.C. \& TAKEDA S. 1994: The adult eclosion rhythm in Hyphantria cunea (Lepidoptera: Arctiidae): Endogenous and exogenous light effects. Biol. Rhythm Res. 25: 464-476.

MUlleR K. 1973: Circadian rhythms of locomotor activity in aquatic organisms in the subarctic summer. Aquilo Ser. Zool. 14: $1-18$.

PittendRigh C.S. 1960: Circadian rhythms and the circadian organisation of living systems. Cold Spring Harbor Symp. Quant. Biol. 25: 159-184

PitTENDRIGH C.S. 1967: Circadian systems I. The driving oscillation and its assay in Drosophila pseudoobscura. Proc. Nat. Acad. Sci. USA 58: 1762-1767.

Plautz J.D., Kaneko M., Hall J.C. \& Kay S.A. 1997: Independent photoreceptive circadian clocks throughout Drosophila. Science 278: 1632-1635.

Pompanon F., Founllet P. \& Bouletreau M. 1995: Emergence rhythms and protandry in relation to daily patterns of locomotor activity in Trichogramma species. Evol. Ecol. 9: 467-477.

Pyza E. \& Cymborowski B. 2001: Circadian rhythms in behaviour and in the visual system of the blow fly, Calliphora vicina. J. Insect Physiol. 47: 897-904.

ReZnIK S.YA., ZinOVJeVA K.B., UMarova V.A. \& ZaslavsKI V.A. 1998: Dependence of eclosion rhythm on photoperiod and thermoperiod in species of the genus Trichogramma Westw. (Hymenoptera: Trichogrammatidae). Entomol. Rev. 78: $13-19$.

RiIHIMAA A. 1996: Genetic Variation in Diapause, Coldhardiness and Circadian Rhythm in Chymomyza costata. University of Oulu, Oulu, $52 \mathrm{pp}$.

Roces F. \& NUNEz J.A. 1996: A circadian rhythm of thermal preference in the ant Camponotus mus: Masking and entrainment by temperature cycles. Physiol. Entomol. 21: 138-142.

ROUNBEHLER M.D. \& Ellington J.J. 1973: Some biological effects of selected light regimes on Trichogramma semifumatum (Hymenoptera: Trichogrammatidae). Ann. Entomol. Soc. Am. 66: 6-10.

Ruberson J.R., TAuber M.J. \& Tauber C.A. 1988: Reproductive biology of two biotypes of Edovum puttleri, a parasitoid of Colorado potato beetles eggs. Entomol. Exp. Appl. 46: 211-219.

SAUnders D.S. 1982: Insect Clocks. Pergamon Press, Oxford, $409 \mathrm{pp}$.

SAUNDERS D.S. \& Hong S.-F. 2000: Effects of temperature and temperature steps on circadian locomotor rhythmicity in the blow fly Calliphora vicina. J. Insect Physiol. 46: 289-295.

Sidote D., Majercak J., Parike V. \& Edery I. 1998: Differential effects of light and heat on the Drosophila circadian clock proteins PER and TIM. Mol. Cell. Biol. 18: 2004-2013.

TAVARES J. \& VOegele J. 1991: Influence of the photoperiod on the egg laying rhythm and emergence of three Trichogramma species (Hymenoptera: Trichogrammatidae). Redia 74: 309-314.

Tomioka K., Sakamoto M., Harui Y. \& Matsumoto N. 1998: Light and temperature cooperate to regulate the circadian locomotor rhythm of wild type and period mutants of Drosophila melanogaster. J. Insect Physiol. 44: 587-596.

Truman J.W., Taghert P.H., Copenhaver P.F., Tublitz N.J. \& SCHWARTz L.M. 1981: Eclosion hormone may control all ecdyses in insects. Nature 291: 70-71.

TSHERNYSHEv W.B. 1984: Diurnal Rhythms of Activity in Insects. Publishing House of Moscow State University, Moscow, 216 pp. [in Russian]

WIEDENMANN G. \& LoHER W. 1984: Circadian control of singing in crickets: two different pacemakers for early-evening and before-down activity. J. Insect Physiol. 30: 145-151. 
Yoshida T. \& Kimura M. 1994: Some effects of low temperature on the photoperiodic clock in Drosophila triauraria. Physiol. Entomol. 19: 83-87.

Zaslavski V.A., Zinovieva K.B., Reznik S.Ya. \& Umarova T.YA. 1995: Effect of the photoperiod and thermoperiod on the eclosion rhythm in Trichogramma evanescens (Hymenoptera: Trichogrammatidae). Entomol. Exp. Appl. 74: 99-104.

ZaslaysKi V.A., ZinOVJeVA K.B., UMAROVA T.YA. \& RezNIK S.YA. 1999: Interaction of circadian rhythm synchronised by photoperiod and by thermoperiod with direct influence of light and temperature as factors determining rhythm of adult eclosion in two species of Trichogramma (Hymenoptera: Trichogrammatidae). Entomol. Rev. 79: 1-10.

Zimmerman W.F., Pittendrigh C.S \& Pavlidis Th. 1968: Temperature compensation of the circadian oscillation in Drosophila pseudoobscura and its entrainment by temperature cycles. J. Insect Physiol. 14: 669-684.
Zinovjeva K.B., Reznik S.A., Zaslavski V.A. \& Umarova T.YA. 1996: Effect of photoperiod and thermoperiod on the eclosion rhythm of adults in Alysia manducator (Hymenoptera, Braconidae) and Trichogramma evanescens (Hymenoptera, Trichogrammatidae). Zool. Zh. 75: 1496-1504. [in Russian, English abstr.]

Zhukovskaya M. 1995: Circadian rhythm of sex pheromone perception in the male American cockroach, Periplaneta americana L. J. Insect Physiol. 41: 941-946.

Zotov V.A. 1983: Exogenous and endogenous components of the circadian rhythm of activity in Coccinella septempunctata (Coleoptera: Coccinellidae). Zool. Zh. 62: 1654-1661. [in Russian]

Received November 9, 2001; revised August 12, 2002; accepted August 20, 2002 